\title{
Regulatory matters affecting distribution planning with distributed generation
}

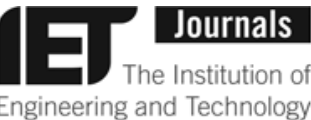

Engineering and Technology

ISSN 2515-0855 doi: 10.1049/oap-cired.2017.0358 www.ietdl.org

\author{
Manuel Alvarez ${ }^{凶}$, Sarah K. Rönnberg ${ }^{1}$, Math H.J. Bollen ${ }^{1}$, \\ Rafael Cossent' ${ }^{2}$ Jin Zhong ${ }^{3}$ \\ ${ }^{1}$ Department of Engineering Sciences and Mathematics, Luleå University of Technology, \\ LSkellefteå, Sweden \\ ${ }^{2}$ Institute for Research in Technology (IIT), ICAI School of Engineering, Pontifical University of \\ Comillas, Madrid, Spain \\ ${ }^{3}$ Department of Electrical and Electronic Engineering, The University of Hong Kong, Hong Kong, China \\ ¿-mail: manuel.alvarez@Itu.se
}

\begin{abstract}
Under the present European directive concerning common rules for the internal market in electricity, distribution companies are not allowed to own distributed generation (DG) but encouraged to include it as a planning option to defer investment in traditional grid reinforcements. Distribution system operators (DSOs) have used the provision of capacity contracted to DG as a viable alternative under current regulatory arrangements. Here, the topics bonding DSOs and DG owners under the present regulation will be explored and a planning structure that considers distribution capacity contracts as a planning option will be proposed. This will serve as a road map for DSOs to implement its preferred planning tools in an optimisation context, considering costs of investment, reliability, operation, and capacity provision while complying with current regulation.
\end{abstract}

\section{Introduction}

The growing penetration of distributed energy resources (DER) represents a challenge for the distribution system operator (DSO) regarding the adequacy of the grid to host it, and the management of operational issues affecting the quality of service. As established by the European Directive [1], the unbundling of the distribution company from other non-related activity as generation forbids the distribution company to own DG which is not intended to provide network services. The DSO has to accept DG in the same way as they have to accept changes in consumption. The behaviour of DG is uncertain and hinders the DSO's ability to perform appropriate control and adequation of the grid [2]. DG can help reduce investment in connection to the transmission grid and can naturally defer investments in grid reinforcements. DG located near demand can reduce network losses and provide ancillary services to the DSO [3]. High penetration of DG can increase the reinforcement costs to allow its connection to the grid and increase network losses due to reverse power flows. This can result in higher capital expenditure for the DSO, and if not socialised among the customers, it can have a negative impact on its revenue [4]. Unbundling rules, in spite of these shortcomings, make sense regarding competition issues related to grid access and connection. Since the DSO cannot directly influence either the location or the operation of DG, this conflict might be overcome by giving financial incentives to influence the DG operators to settle in a particular location and behave in response to DSO needs [3]. Some works have addressed the issues that hinder the DG integration [5] and some recommendations have been proposed in order to adapt the present regulation according to this [6]. In the absence of unbundling rules, due to lack of investors in DG or when competition at retail level is not promoted, DG can be considered as a planning option that can be installed and operated by the DSO [7]. In the presence of unbundling, some methodologies address load shaving strategies implementing DG [8] and others the investment deferral through capacity contracts. A market-oriented approach called contract for deferral scheme allows the DSO to contract capacity from a portfolio of available
DERs [9]. Another market mechanism called reliability options for distributed generation [10] allows the DSO to convene an auction in areas with capacity shortage, letting the DG within those areas to bid a firm capacity.

There is still a lack of planning methodologies that match closer the actual regulation in Europe while trying to include DG in it. This work will propose a structure to adapt capacity procure mechanisms or distribution capacity contracts (DCCs), into the distribution grid planning methodology.

The remainder of this article is divided as follows: the next section will provide a description of the DSOs. Then, the planning problem including DG will be explained further. A planning structure including DCCs will be proposed. Finally, conclusions and recommendations will be presented at the end of this paper.

\section{Distribution system operators}

The DSOs are responsible for managing, controlling, and planning the future distribution systems. From a technical viewpoint, the operation of the distribution system concerns two critical aspects: control of the voltage variations and the management of the congestions. When DG production exceeds local demand, system overvoltage and congestion may occur. DSOs have to comply with their responsibilities [11], which are: development of the system, connection and provision of capacity, monitoring and control to provide operational security, balancing and congestion management, and to guarantee the availability and quality of service. Other important role of the DSO in some EU countries is to serve as an impartial facilitator in the retail market activity through managing metering, providing information to market participants and helping in the process of switching supplier. DSOs might serve as an information hub that gathers and distributes data to the stakeholders connected to it, providing efficient access to the system and granting confidentiality among participants [12]. Some examples of implemented information hubs are the NUBIX model in Norway and the EMIX portal in Sweden. These information platforms could help enhance 
communication and facilitate the trade of services to boost system operation.

\subsection{DSO current situation}

Given the asymmetry of information between the regulator and the DSOs, an incentive-based regulation that promotes efficiency has been implemented by most European countries [13]. The DSO is obliged to provide connection to any new user including DG. Capital expenditures (CAPEX) are increased to adapt the grid for hosting the DG implementing reinforcements as transformers, lines, and switchgear. Operational expenditures (OPEX) are increased since network losses tend to increase when high density of DG is present, and to manage the inherent complexity in control, automation, protection devices, power quality mitigating devices, and maintenance. The DSO, being a part of a vertically integrated undertaking, must remain independent from other activities not related to distribution. This avoids the DSO favouring a generation business owned by the same undertaking, also avoiding the ability to perform a joint network and generation planning. As a consequence, DSOs are disregarding DG and their advantages leading to inefficient planning and operation of the system [14].

\subsection{DSO remuneration}

In the traditional revenue structure of the distribution company, the money flows from the customers, either DG or consumers, to the service providers. According to [15] (Fig. 1), the revenues are divided in connection charges and use of service (UoS) charges. Connection charges are paid once and are intended to cover either the direct cost of connection to the distribution grid (shallow), including upstream network reinforcements (shallowish charges), or including equipment and reinforcements upstream the point of connection (deep charges). This characterisation might change from one country to another. The different types of connection costs are further explained in [16]. In some of the EU member states, a capacity threshold is defined in order to apply one type of connection charge or the other. The UoS is paid regularly by the grid users and is a tariff based on the cost and profit allowance set by regulation. It guarantees the DSO recovery of costs and facilitates DG integration. Other operational expenses as ancillary services, reactive power support, balancing, and energy losses are paid to the transmission system operator (TSO), DGs, and other large power producers at transmission level. An overview of the revenue structure in some of the EU countries is presented in [5]. Three typical distribution regulation approaches can be distinguished:

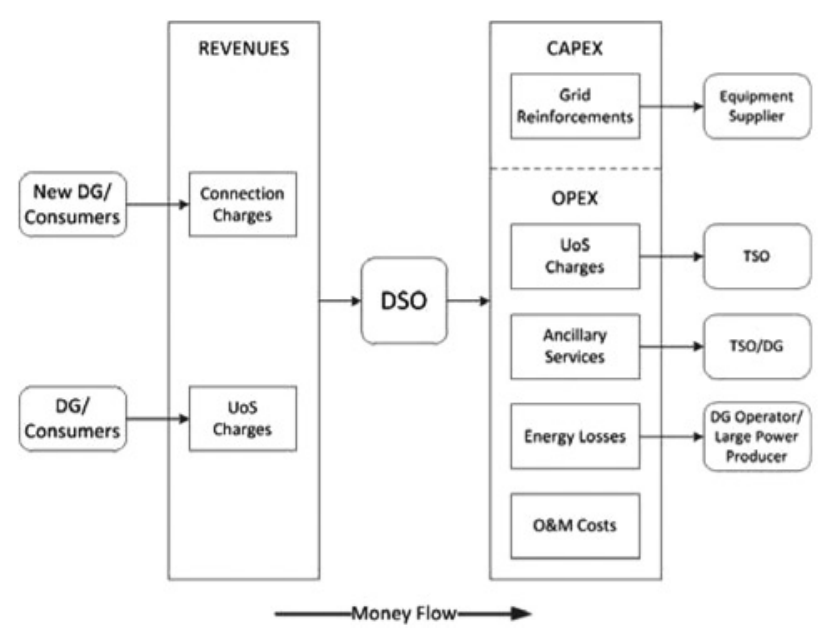

Fig. 1 DSO revenues and expenditures [15]
Rate-of-return regulation: the regulator approves a profit over the audited expenses.

Incentive-based regulation: under a price-cap regulation, the regulator sets a cap on the service price the utility is allowed to charge. Under a revenue-cap regulation, the regulator adjusts the allowed revenues for the utility.

Yardstick regulation: Is also a form of incentive-based model where the revenue is defined by comparing the DSO performance to equivalent suppliers. This is similar to a revenue cap regulation where benchmarking is used.

\subsection{Quality of service}

The technical quality of service provision comprises two categories, continuity of service and voltage quality. Regarding voltage quality aspects, the European standard EN50160 establishes the characteristics of the voltage profile that should be met by the DSOs [17]. Levels and issues associated with e.g. flicker, harmonics, dips, and over-voltages have been addressed in order to guarantee proper conditions for the operation of the equipment connected to the grid [18]. Regarding the continuity of service, reliability indices are computed to measure the performance of the system. Frequency and duration indices as system average interruption duration index (SAIDI) and system average interruption frequency index (SAIFI) are typically used for that purpose [19]. DER being located closer to the load centres tends to impact specific costumers rather than the overall group of connected costumers, and so forth they have a minimum impact on indices like SAIFI and SAIDI. Customer average interruption duration and frequency indices become suitable for measuring the real impact of DER on reliability [20]. Penalisations within the regulatory scheme can be used to incentivise the DSO to keep within margin those indices. The planning strategy might become oriented to minimise the compromise between investment and penalisations. A discussion on the tradeoffs between reliability cost and benefit in distribution planning is presented in [21]. The penetration of DG impacts several operational aspects of the distribution and transmission grid. The impact of DG penetration is partially bonded to the protection system behaviour; also voltage quality participates in undesirable scenarios that impact the continuity of service [22]. The risk of overload is also impacted by DG. It can reduce it by producing locally during peak hours, or it can increase it by exporting to the transmission grid.

\subsection{Uncertainties affecting the DSO}

Conventionally, distribution planning consisted in identifying the worst possible long-term future operating conditions, adding a security margin, and reinforcing the grid accordingly. However, in order to solve network problems close to real time (and thus prevent or defer network investments), load/DG forecasts need to be performed much more regularly and presumably with a higher locational granularity. This is a challenge, especially concerning DG production. The quality of the forecast depends on the time horizon and the phenomena studied among other factors. Up to a week, forecasts of temperature and wind might have an error between 11 and $20 \%$. For other phenomena like solar radiation or forecasts for longer term horizons, the error percentage will grow and other previsions based on scenarios evaluation must be taken. Weather forecasting affects dynamic line rating, load and production forecasting, failure rates of equipment, and reliability indices used in planning studies [23]. These predictions allow the DSO to evaluate strategies as network reconfiguration, provision of additional production, and demand response (DR). DR is also correlated to weather behaviour due to heating, cooling, EV charging, and renewable production such as rooftop photovoltaic panels. DG owners also use predictions of market prices, consumption, and weather affecting the renewable production in order to define optimal operating strategies. Regulation is perhaps 
one of the most abstract and difficult to assess type of uncertainty. Changes in the regulation can occur in the future, perturbing already-made planning decisions.

\section{Planning with DG}

Higher efficiencies are still on the side of large generators. DG efficiencies have improved, given perfected technologies for fuel conversion, and materials that reduce wear and maintenance. Although the economy of scale favours large centrals, DG is located closer to the customers, so the competition against large generators is not only achieved in terms of efficiency or in terms of cost per $\mathrm{kWh}$ : it is more economical if compared along with its associated $\mathrm{T} \& \mathrm{D}$ requirements. Technical and economic aspects in this regard can be found in [24]. How DG impacts the performance of the power distribution grid and what possible remedies can be implemented to ensure the quality of service have been extensively treated in [22]. One of the key distribution planning issues with DG is that they can trade energy in a liberalised market while connected to an open access distribution system that remains a regulated monopoly whose DSO is not allowed to participate in the competition using it [25].

\subsection{Active management approach}

The active management of the distribution grid enables the DSO to make use of control variables located in the DG along with other traditional control elements as transformer taps, reconfiguration, and voltage regulators. For instance, wind power cannot be easily controlled but other DG as combined heat and power (CHP) or biomass generators can be dispatched to meet fluctuations. The idea is to maximise the loadability of the circuits without affecting the security and quality of the service. The DSO should foster the installation of energy production and incentive production according to network constraints. The DSO must act as a network operator and a market facilitator that manages a local market for network services. It is technical and economical inefficient to track load and renewable production fast changes at distribution level with large base-load generators at transmission level. DG can be equipped to provide such local balancing. A proposal for a dynamic distribution system and market place presented in [26] addresses the balancing between bulk generation and DERs. An active management approach of the distribution system, considering a scheduling framework at the TSO/DSO interface, has been considered in [27].

\subsection{Regulation improvements}

A report elaborated in [28] provides guidelines to improve the DG integration in distribution grids. These guidelines are oriented to socialise the impact of DG and to honour the proper payment of service through tariffs and connection charges:

- an incentive-based regulation with UoS charges to DG, differentiated by time of use and voltage level, along with economic incentives for ancillary services provision;

- DSO compensation for increased CAPEX and OPEX due to a DG penetration higher than $15-20 \%$;

- performance-based regulation for quality of service targets;

- allow DG to pay and receive UoS charges;

- bilateral contracts between DGs and DSOs.

DSO compensation, through specific allowances and tariff adjustments, has been studied in [29]. Also, a benchmark study to evaluate the impact of different regulatory schemes was presented in [30].

\subsection{Planning methodologies}

The DSO can implement new smart grid technologies and strategies as alternative solutions in planning the distribution grid with uncertainties. A structure to give the DSO a roadmap for implementing such solutions while understanding its benefits has been proposed in [31]. Distribution planning that considers DG as a planning option is supported by the assumption that the regulation allows the DISCO to own generation and manage it. Investment deferral [14] and peak cutting [8] are benefits perceived by the DSO if doing so. A proposed model considering DG as non-wired solution for dynamic planning is presented in [32]. Consideration of the reactive capability of DG in voltage control has been studied in [33]. The impact of DG integration along with load response uncertainty has been considered in [34]. A multi-stage planning methodology which considers the unit commitment (UC) of generation units to assess the impact of new DG in operational costs has been presented in [35]. A multi-objective optimisation problem that captures simultaneously the cost of the energy not served and the cost of the assets is presented in [20].

\section{Planning with DCCs}

The DCC creates a virtual communication channel between the DSO and the DG owner when they enter into contract. This will let them convene a strategy that favours the operation and planning of the distribution grid in the lead time. The DCC comprises three stages: a capacity call auction, the auction clearing and awarding, and the DSO online power request. The DSO calls for auction at certain locations in need of capacity provision. DG owners within those areas place their bids composed by a single capacity at a certain price. The DSO executes the auction clearing and awards the DG owners the correspondent capacity contracts. Finally, the DG owner will provide in the lead time, and upon request of the DSO, at least a firm power within the capacity contracted. This will allow the DSO to do fine tuning of the grid during operation, having a share of DG under its control. The DCC is applied under the assumptions:

- The regulation allows this type of capacity contract.

- The DSO organises and calls capacity auctions. DR, storage operators, renewable sources, and virtual power plants (VPPs) are possible capacity providers.

\subsection{Interaction between DG owners, DSOs, and DCCs}

The willingness of the DG owner to participate in a DCC relies on the improvement on its remuneration. A study assessing the impact of DCCs on VPPs remuneration has been presented in [36]. The bidding price and the penalties for non-compliance of the contract are its main concerns. DCCs are expected to be applied by distribution companies under an incentive-based regulation where the revenues are limited and its application can increase DSO's profitability. In a rate-of return scheme, the DSO can be more interested in implementing traditional reinforcements if the rate set by the regulator is high. The DSO has to consider maintenance costs, network losses, and quality of supply while calculating expansion costs.

\subsection{Planning structure}

The DSO requires adapting the grid with regard to the regulatory agreements, meeting design criteria, and exploiting DG benefits to find cost-effective plans. Here, a planning structure (Fig. 2) is proposed in order to introduce DCCs as a planning alternative that should be considered within an optimisation framework to find short-term grid solutions. This planning methodology attempts to determine if DCCs are a worthwhile option to defer grid investment. 


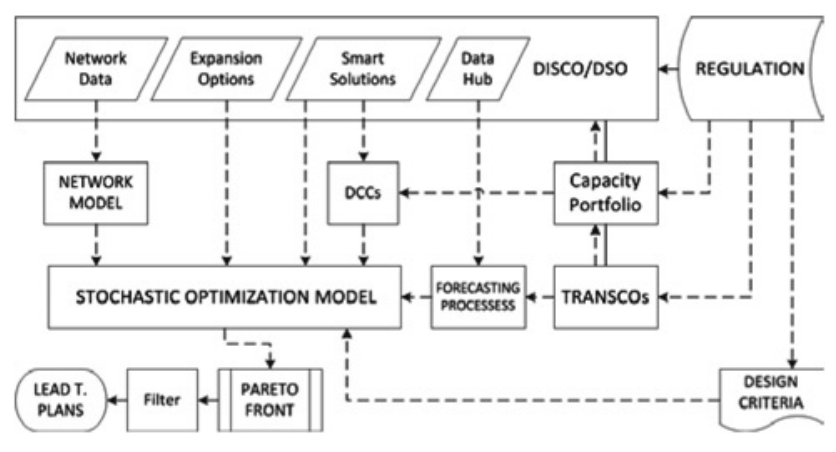

Fig. 2 Proposed planning structure

The main features of the proposed planning structure are:

- This planning structure has been conceived for the short-term lead time, between 1 and 3 years. This lead time is suitable for gearing, DCCs, smart solutions, expansion, and operational decisions.

- The DSO gathers the data from the TSO/DSO interface, customers, producers, and forecast their behaviour for the planning lead-time.

- A balanced model for the grid might be used under the assumption of proper load balancing in low voltage. Equipment to mitigate unbalance can be considered within the connection charges. - The planning problem can be formulated as a stochastic multistage mixed integer linear programming problem. A manner of considering the impact of early-stage decisions on future operation and planning costs could be achieved by implementing a stochastic dual dynamic programming approach [37].

- The award of the DCCs and their online power request are decision variables.

- Reliability worth, investment, and operation costs are objectives to be consider by the DSO.

- Considering an ex-post decision-making process, this methodology intends to produce several expansion options to be evaluated by a long-term plan study that will determine if they fit long-term needs and provide long-lasting value.

- The output of this short-term planning structure is a Pareto front of investment and operation costs. This Pareto front could be filtered to reduce the spectra of non-dominated solutions as explained in [38]

\section{Conclusions and recommendations}

The regulation unbundling limits the communication between stakeholders to avoid unethical strategies that jeopardise the inherent fairness of the liberalised market. Certain trade of information among actors could help reducing the predominant uncertainty affecting the DSO in planning stages. There is a need to improve communication between DSOs and DG owners in order to reduce such uncertainty and improve the system performance. The DCCs are expected to have two effects on distribution systems: they will incentivise the development of new capacity providers at specific locations, and they will give the DSO an equivalent share of DG under its control. The proposed planning methodology considers DCCs as part of the available smart solutions. The methodology proposes to embed the auction process to grant DCC contracts within the optimisation framework in order to find more cost-effective combined solutions for a dynamic planning problem. The optimisation algorithm contrasts DCCs against traditional reinforcements. If worthwhile, DCCs could be chosen over grid reinforcements. The planning methodology is a part of an ex-post decision-making process whose output is a Pareto front of investment and operational costs.

\section{References}

1 'Directive 2003/54/EC of the European Parliament and of the Council of 26 June 2003 concerning common rules for the internal market in electricity and repealing Directive 96/92/EC'. vol. 46, 15 July 2003

2 Saad, Y.E.-M., Salama, M.M.A., Elshatshat, R.A., et al.: 'The operation of a distribution company under uncertainty: an overview'. 2009 IEEE Power \& Energy Society General Meeting, 2009, vol. 1-8, pp. 2563-2569

3 Van Werven, M.J.N., Scheepers, M.J.J.: 'The changing role of distribution system operators in liberalised and decentralising electricity markets'. 2005 Int. Conf. on Future Power Systems (FPS), 2005, pp. 350-355

4 Scheepers, M., Jansen, J.: 'Enhancement of sustainable electricity supply in Europe through improvement of distribution network regulation'. 2007 IEEE Power Engineering Society General Meeting, 2007, vol. 1-10, pp. 3207-3208

5 Cossent, R., Gomez, T., Frias, P.: 'Towards a future with large penetration of distributed generation: is the current regulation of electricity distribution ready? Regulatory recommendations under a European perspective', Energy Policy, 2009, 37, pp. 1145-1155

6 Frias, P., Gomez, T., Cossent, R., et al.: 'Improvements in current European network regulation to facilitate the integration of distributed generation', Int. J. Electr. Power Energy Syst., 2009, 31, pp. 445-451

7 Porkar, S., Poure, P., Abbaspour-Tehrani-fard, A., et al.: 'A novel optimal distribution system planning framework implementing distributed generation in a deregulated electricity market', Electr. Power Syst. Res., 2010, 80, pp. 828-837

8 Ouyang, W., Cheng, H., Zhang, X., et al.: 'Distribution network planning method considering distributed generation for peak cutting', Energy Convers. Manage., 2010, 51, pp. 2394-2401

9 Poudineh, R., Jamasb, T.: 'Distributed generation, storage, demand response and energy efficiency as alternatives to grid capacity enhancement', Energy Policy, 2014, 67, pp. 222-231

10 Trebolle, D., Gomez, T., Cossent, R., et al.: 'Distribution planning with reliability options for distributed generation', Electr. Power Syst. Res., 2010, 80, pp. 222-229

11 EURELECTRIC: 'Active distribution system management. A key tool for the smooth integration of distributed generation', 2013

12 EURELECTRIC: 'The role of distribution system operators (DSOs) as information hubs', 2010

13 'CEER Report on Investment Conditions in European Countries'. Council of European Energy Regulators, 2016

14 Piccolo, A., Siano, P.: 'Evaluating the impact of network investment deferral on distributed generation expansion', IEEE Trans. Power Syst., 2009, 24, pp. $1559-1567$

15 de Joode, J., Van der Welle, A., Jansen, J.: 'Distributed generation and the regulation of distribution networks' (InTech, 2010), 1 February 2010

16 Picciariello, A., Alvehag, K., Soder, L.: 'State-of-art review on regulation for distributed generation integration in distribution systems'. 2012 9th Int. Conf. on the European Energy Market (EEM), 2012

17 Frias, P., Gomes, T., Rivier, J.: 'Regulation of distribution system operators with high penetration of distributed generation'. 2007 IEEE Lausanne Powertech, 2007, vol 1-5, pp. 579-584

18 Gomez, T., Rivier, J.: 'Distribution and power quality regulation under electricity competition. A comparative study'. 2000 Proc. Ninth Int. Conf. on Harmonics and Quality of Power, 2000, vol. 2, pp. 462-468

19 Willis, H.L.: 'Power distribution planning reference book' (CRC Press, 2004, 2nd edn.)

20 Heydt, G.T.: 'The next generation of power distribution systems', IEEE Trans. Smart Grid, 2010, 1, pp. 225-235

21 Chowdhury, A.A., Koval, D.O.: 'Current practices and customer value-based distribution system reliability planning', IEEE Trans. Ind. Appl., 2004, 40, pp. $1174-1182$

22 Bollen, M.H., Hassan, F.: 'Integration of distributed generation in the power system' (Wiley, 2011)

23 Alvehag, K., Soder, L.: 'A reliability model for distribution systems incorporating seasonal variations in severe weather', IEEE Trans. Power Deliv., 2011, 26, pp. 910-919

24 Willis, H.L., Scott, W.G.: 'Distributed power generation: planning and evaluation' (Marcel Dekker, New York, 2000)

25 Willis, H.L., Philipson, L.: 'Understanding electric utilities and de-regulation' (CRC Press, 2005)

26 Beihoff, B., Jahns, T., Lasseter, R., et al.: 'Transforming the grid from the distribution system out' (Wisconsin Energy Institute, 2014)

27 Saint-Pierre Mancarella, A.P.: 'Active distribution system management: a dual-horizon scheduling framework for DSO/TSO interface under uncertainty', IEEE Trans. Smart Grid, 2016, PP, (99), pp. 1-12

28 Gómez, T., Rivier, J., Frías, P., et al.: 'Guidelines for improvement on the short term of electricity distribution network regulation for enhancing the share of DG' (European Commission, 2007)

29 de Joode, J., van der Welle, A., Jansen, J.: 'Business models for DSOs under alternative regulatory regimes' (Energy Reserach Centre of the Netherlands, 2007)

30 Picciariello, A., Alvehag, K., Soder, L.: 'Impact of network regulation on the incentive for DG integration for the DSO: opportunities for a transition toward a smart grid', IEEE Trans. Smart Grid, 2015, 6, pp. 1730-1739

31 Alvarez, M., Bollen, M., Rönnberg, S., et al. 'A smart distribution toolbox for distribution system planning'. CIRED 23rd Int. Conf. on Electricity Distribution, Lyon, France, 2015

32 Soroudi, A., Ehsan, M.: 'A distribution network expansion planning model considering distributed generation options and techo-economical issues', Energy, 2010, 35, pp. 3364-3374 
33 Zou, K., Agalgaonkar, A.P., Muttaqi, K.M., et al.: 'Distribution system planning with incorporating DG reactive capability and system uncertainties', IEEE Trans. Sustain. Energy, 2012, 3, pp. 112-123

34 Martins, V.F., Borges, C.L.T.: 'Active distribution network integrated planning incorporating distributed generation and load response uncertainties', IEEE Trans. Power Syst., 2011, 26, pp. 2164-2172

35 El-Zonkoly, A.M.: 'Multistage expansion planning for distribution networks including unit commitment', IET Gen. Transm. Dis., 2013, 7, pp. 766-778
36 Alvarez, M., Rönnberg, S., Cossent, R., et al.: 'Remuneration assessment of a VPP providing distribution capacity services'. IEEE PES PowerTech Manchester 2017, Manchester, UK, 2017

37 Newham, N., Wood, A.: 'Transmission investment planning using SDDP', vol. 1-2 (Australasian Universities Power Engineering, 2007), pp. 255-259

38 Carrano, E.G., Guirnaraes, F.G., Takahashi, R.H.C., et al.: 'Electric distribution network expansion under load-evolution uncertainty using an immune system inspired algorithm', IEEE Trans. Power Syst., 2007, 22, pp. 851-861 